\title{
PAROXYSMAL TACHYCARDIA CAUSED BY PENTAMETHYLENE-TETRAZOL
}

\author{
BY \\ F. KLEIN \\ From the University Clinic, Groningen, Holland \\ Received April 8, 1940
}

In 1930 Wolff, Parkinson, and White described the occurrence of bundle branch block with a shortened $\mathrm{P}-\mathrm{R}$ interval in persons with normal health, and subsequently other authors reported analogous cases. It has been generally assumed that no pathological significance, in the sense of a morbid affection of the cardiac muscle, should be ascribed to this electrocardiographic irregularity. A peculiarity noted by every observer, however, was that nearly all patients with this abnormality had at times either paroxysmal tachycardia or paroxysmal fibrillation or flutter.

In a schizophrenic patient in whom the bundle branch block with shortened $\mathbf{P}-\mathbf{R}$ interval had been found, a paroxysm of tachycardia was observed four times, each time after an intravenous administration of pentamethylene-tetrazol. Three of the attacks were recorded.

A man, aged 43, was admitted to hospital in November 1937; he had been ill for half a year already with a diagnosis of schizophrenia. Physical examination revealed no peculiarities, neither did the examinations of the blood and spinal fluid. The blood pressure was 130/80. Roentgenologically the heart proved to be of normal size. In March, 1938, the treatment of schizophrenia by the production of convulsions with pentamethylene-tetrazol was started. Nine complete convulsive seizures were produced after intravenous administration of $5,6,7$, or 8 c.c. of a 10 per cent. solution. The psychiatrist in charge did not observe any irregularity of the heart at the time; but after the first attack an increased pulse rate was noted (160 beats per minute). When, on May 3, I saw the patient, his pulse was still very high six hours after the tenth epileptic insult. The rate was not quite regular, and ranged between 160 and 170 beats per minute. The frequency of the heart was 206 beats per minute and entirely regular. There were no signs of decompensation. A more detailed examination was rendered impossible through the patient's negativism. The seizure was stopped through pressure on the eyeballs, the pulse rate falling to 82 beats per minute. The first cardiogram was taken the next day, and several others in the following months. As a rule, the P-R interval was shortened and QRS was widened with a negative $T$ wave (see Fig. 2A): 


$\begin{array}{lccc}\text { Lead } & \begin{array}{c}\text { P-R } \\ \text { interval } \\ \text { (seconds) }\end{array} & \begin{array}{c}\text { Width of } \\ \text { QRS } \\ \text { (seconds) }\end{array} & \begin{array}{c}\text { Total } \\ \text { (seconds) }\end{array} \\ \text { I } & 0.08 & 0.13 & 0.21 \\ \text { II } & 0 \cdot 10 & 0.11 & 0.21 \\ \text { III } & 0.12 & 0.08 & 0.20\end{array}$

In each lead the $P$ wave was positive and the $T$ wave negative, while the ascending branch of the $\mathrm{R}$ wave always showed a notch. Occasionally alternating normal and abnormal complexes (Fig. 1A) could be observed, whereas now and then

A

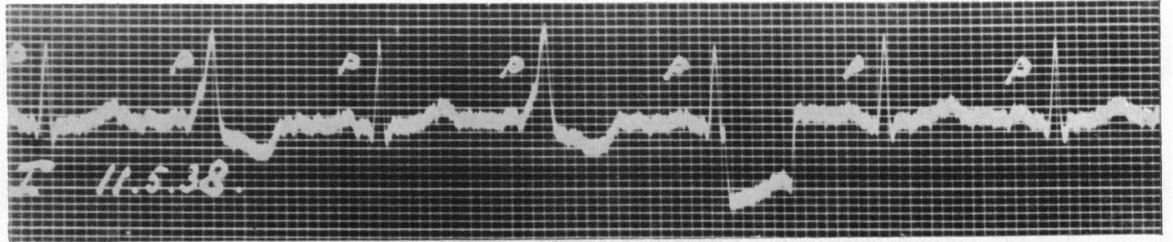

B

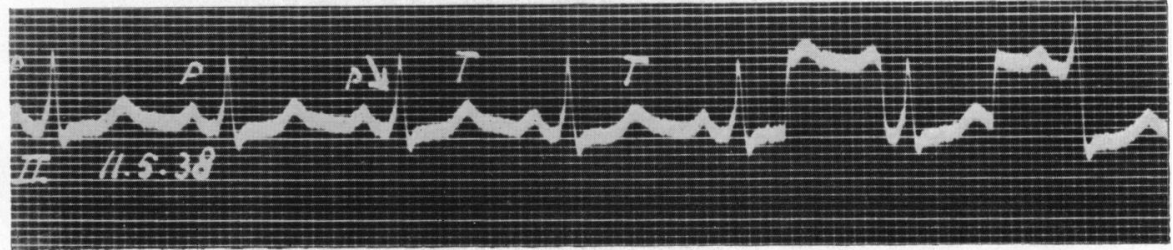

FIG. 1.- Normal rhythm. Lead I shows alternating normal and abnormal complexes. Lead II shows normal complexes with a P-R interval of $0.15 \mathrm{sec}$.

also normal complexes appeared persistently (Fig. 1B). In the normal complexes (lead II) the P-R interval amounted to $0 \cdot 15 \mathrm{sec}$., the QRS width to 0.06 , giving a total of $0.21 \mathrm{sec}$., which is the same as in the case of the abnormal complexes. In every one of them, however, the notch in the ascending branch of the $\mathrm{R}$ wave was noteworthy.

The abnormal electrocardiogram did not show any change after subcutaneous injections of $1 \mathrm{mg}$. of atropine, nor after bodily exertion.

In November, 1938, and in January and March, 1939, paroxysmal tachycardia was registered every time after intravenous administration of pentamethylene-tetrazol. As on the last occasion the insult of an attack was noted as well, and the electrocardiogram of that day is discussed below. The previous observations were similar. Fig. 2 was taken before the injection of 5 c.c. of a 10 per cent. solution of pentamethylene-tetrazol. The rhythm was roughly 90 beats per minute. After the injection at $11 \cdot 16$ no insult could be observed and only the cardiac rhythm had risen to about 106 beats per minute, the width of the QRS complex having fallen from 0.12 to $0 \cdot 08-0.10 \mathrm{sec}$. After five minutes, 6 c.c. of a 10 per cent. solution were injected, which after twenty more seconds produced an insult with clonic and tonic cramps. Fig. 2B was taken as soon as possible. First two rapid beats were traced in succession. The P-R interval was $0 \cdot 08-0 \cdot 10 \mathrm{sec}$., the $Q R S$ width $0.08-0 \cdot 10 \mathrm{sec}$., the $T$ wave negative. After a pause a QRST complex of more normal type followed (QRS, $0.08 \mathrm{sec}$., $T$ wave positive, but $P-R$ interval (shortened to $0 \cdot 10 \mathrm{sec}$.). After these there 


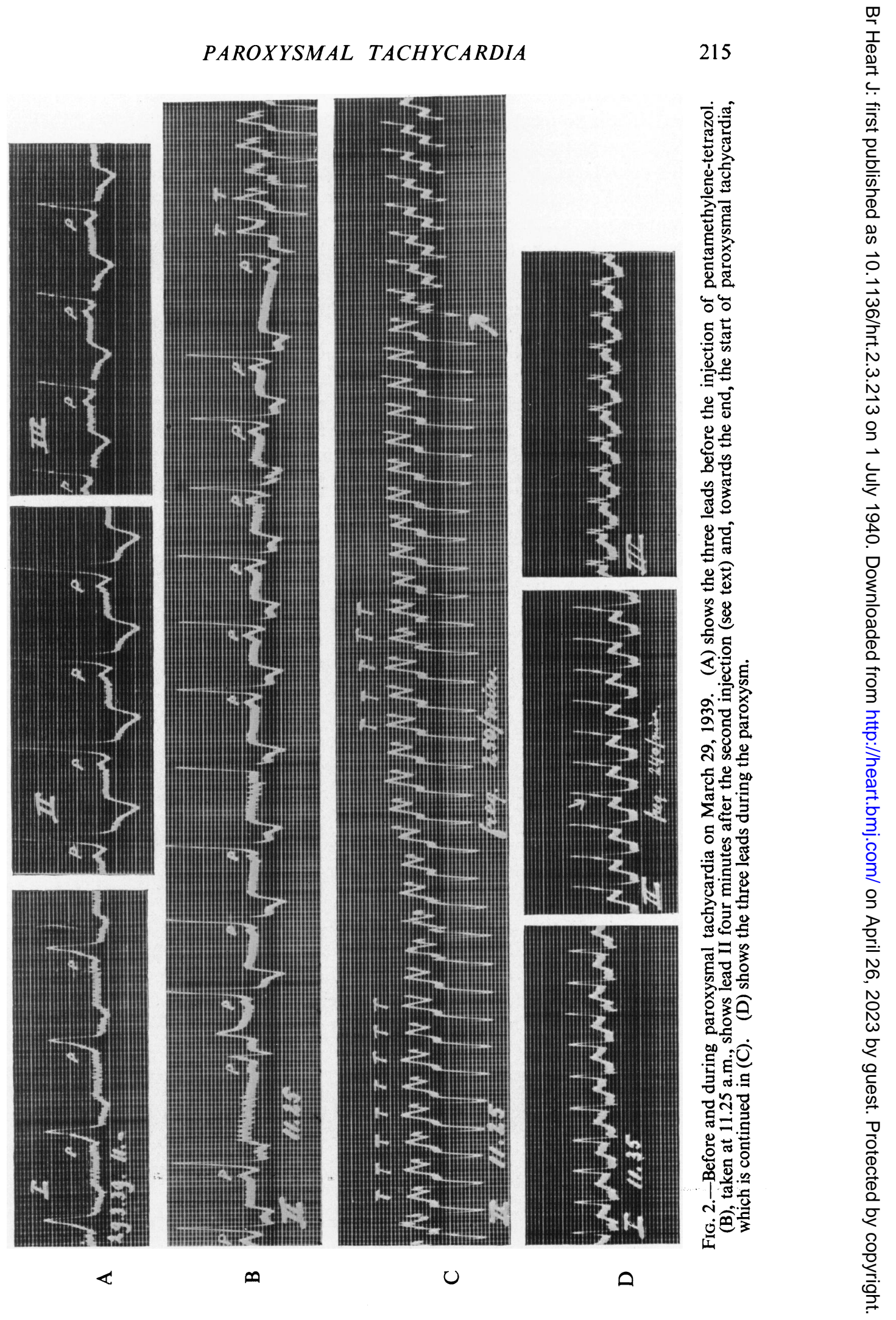


followed ten abnormal complexes, the tracing of which had not been entirely regular. The frequency of the last five amounted to 108 beats per minute. After another pause a complex was registered that resembled the one before these ten complexes and showed a P-R interval of $0.12 \mathrm{sec}$. Directly afterwards there followed an attack of ventricular complexes in a rapid succession (Fig. 2C). The frequency was 250 beats per minute, the QRS width about 0.08 sec., the $\mathrm{T}$ wave and the $\mathbf{P}$ wave doubtful. Suddenly an alteration in the aspect of the complex was observed, although the rhythm remained the same (see arrow, Fig. 2C): with a slight change (see Fig. 2D, lead II, and the beginning of Fig. 4A) this form was stationary.

The three leads (Fig. 2D) were registered during the paroxysm. The entire picture, especially the QRS complex, shows a great similarity to the pattern of the normal complexes which, for example, were to be seen after the end of the attack (Fig. 4D). Here too the notch in the R wave of II is striking (see arrow in lead II, Figs. 2D and 4D). The deviation is especially apparent in the ST interval, and is frequently observed with this disturbance (Scherf, 1937). P was nowhere to be recognized during the paroxysm (see Fig. 2D).

As regards the stopping of the attacks, the first of May 1938 was immediately abolished through pressure on the eyeballs. This was repeated whenever convulsion had set in, but it appeared that pressure of the eyeballs was only successful a few hours after the injection of pentamethylene-tetrazol. Pressure of the " carotid" was always violently resisted by the patient.

In Fig. 4A the first arrow indicates the moment at which the rhythm had become normal again. Initially, as is apparent from Figs. 4, A, B, and C, which link up with each other, the rhythm was irregular, viz. first slow and then quicker, with a few pauses of longer duration (Fig. 4 C), in all probability the outcome of sinus arrhythmia; the P-R interval, which was first $0.08 \mathrm{sec}$., subsequently rose to $0 \cdot 14-0.15 \mathrm{sec}$. In all complexes except the first two, $R$ showed a notch. Remarkable, moreover, is the gradual return to normality of the pathological aspect of $\mathrm{S}-\mathrm{T}$, as is apparent in the four successive arrows in Fig. 4A. One ventricular extrasystole was registered.

The diagnosis made was paroxysmal auricular tachycardia. The sudden beginning and ending excluded sinus tachycardia, and flutter was highlyimprobable.

There is one more electrocardiagram we should like to discuss (see Fig. 3). It was taken just after stopping an attack in November 1938. In addition to an irregular rhythm, caused chiefly by a sino-auricular block, there appeared at the end of the curve a very brief fibrillation-flutter (see arrow).

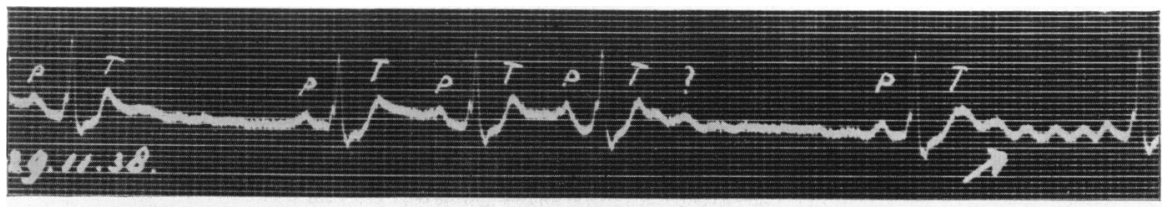

FIG. 3.-Normal rhythm shortly after stopping a paroxysm on November 29,1938 . At first the irregularity seems to be due to sino-auricular block, but later (at the arrow) there is a short period of impure flutter or coarse fibrillation. 
PAROXYSMAL TACHYCARDIA

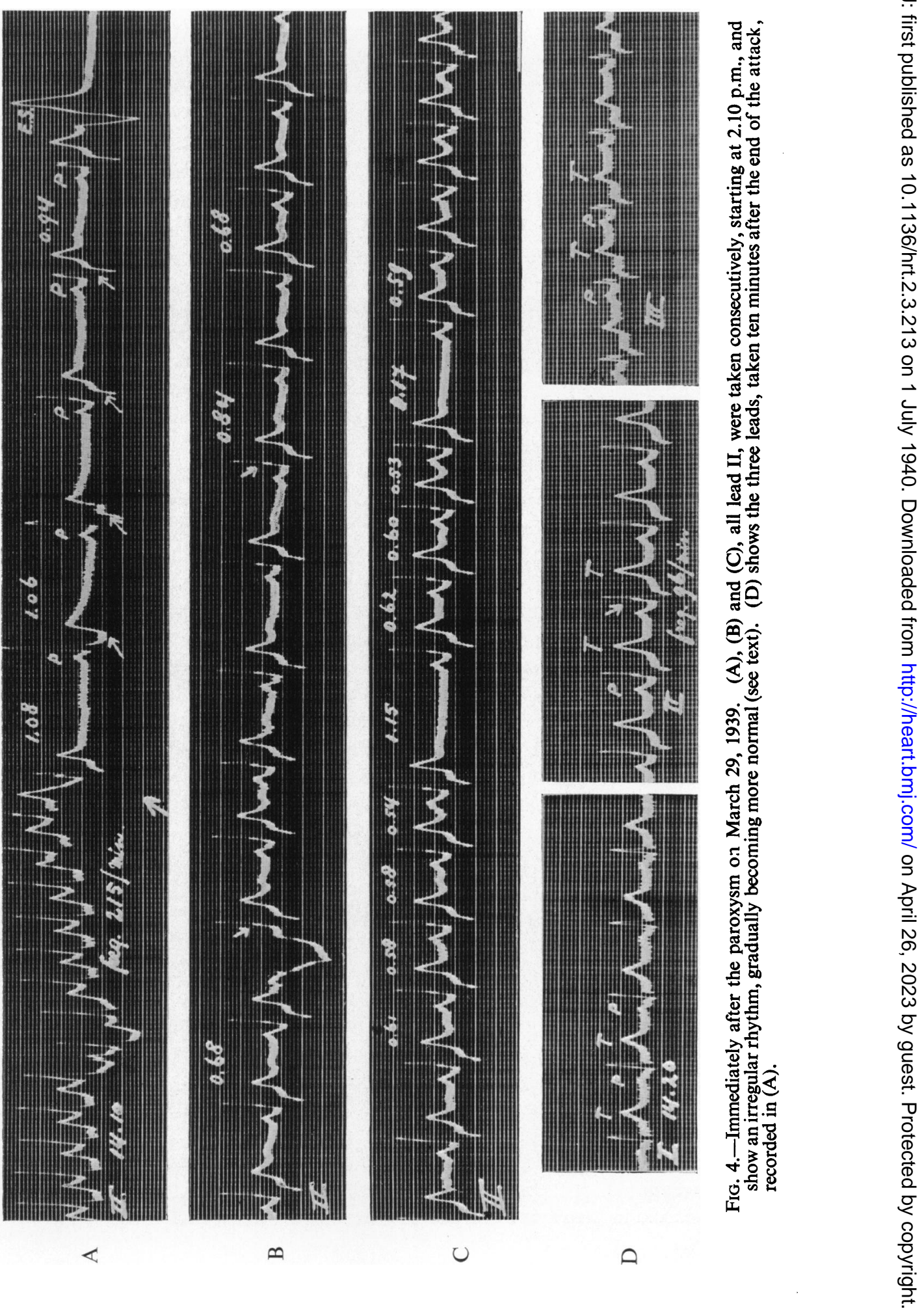




\section{Discussion}

The cardiographic findings in this case are similar to those recorded previously. Here too, as indicated by Wolferth and Wood (1933), there could be observed the same interval from $\mathbf{P}$ to the end of the QRS complex both for the normal and abnormal complexes, and paroxysms of tachycardia with normal, non-widened ventricular complexes.

This instance is mentioned because pentamethylene-tetrazol proved capable of producing these attacks. Several drugs have been described as provoking paroxysmal tachycardia, such as digitalis (Schwab, 1931), quinidine (Lewis, 1921), adrenaline (Danielopolu, 1921), and atropine (Galli, 1918). The same was reported of pentamethylene-tetrazol ever since this drug was injected intravenously in doses of 0.3 to $0.8 \mathrm{~g}$., as is usually the case when applying von Meduna's treatment. These attacks, which set in immediately after the insult, are of short duration (Géraudel, 1938) in most cases, the same as the irregularities observed, such as $\mathrm{P}, \mathrm{S}-\mathrm{T}$, and $\mathrm{T}$ alterations and extrasystoles, block, etc. The longer duration of the attacks in the patient under consideration should be explained from the fact that he was predestined for such attacks, just as other patients with shortened $\mathbf{P}-\mathbf{R}$ interval and bundle branch block.

Paroxysmal tachycardia may be caused-among other things-by the occurrence of an accelerans-impulse in connection with a sensitizing factor in the heart. Rothberger and Winterberg (1911) succeeded in obtaining this through injections of barium chloride into the cardiac muscle. In patients with shortened $\mathrm{P}-\mathrm{R}$ interval and bundled branch block, however, this sensitizing factor is already present. As for the impulse from the accelerans nerve, the intravenous injection of pentamethylene-tetrazol nearly always gives rise to an accelerated rhythm of the heart even before the insult has been produced. Also in the case of our own patient, this acceleration could be noted (see Fig. 2).

Pentamethylene-tetrazol, therefore, if administered in the above quantity and manner was observed to produce the attack; in this patient, however, it appeared to be impossible to obtain the same result through an accelerated rhythm of the heart-100 and 110 beats per minute respectively-caused by bodily exertion or a subcutaneous injection of $1 \mathrm{mg}$. of adrenaline. Thus it ensues that, in all probability, the effect of pentamethylene-tetrazol should not be ascribed to the accelerans impulse exclusively.

As regards the pharmacological action of pentamethylene-tetrazol Hildebrandt (1937) stakes that as a result of the stimulation of the vasomotor centre the vagus centre is being stimulated as well. Camp (1928) demonstrated that pentamethylene-tetrazol in its effect on the autonomous centres of the brain is both a sympathetic and a parasympathetic stimulant. In view of the fact that Rothberger and Winterberg (1911) succeeded in developing paroxysmal tachycardia through electrical stimulation of vagus and sympathetic, it seems likely that the origin of such attacks after pentamethylene-tetrazol is to be found in a similar mechanism of stimulating vagus and sympathetic nerves. Lohr (1936) also accounted for the influence of adrenaline on the development of paroxysmal tachycardia in her experiments through a joint vagotonic and sympatheticotonic action. 
We were unable to ascertain which is the mechanism concerned in the bringing about of spontaneous attacks in patients with shortened P-R interval and bundle branch block. Our patient developed an attack two days after the last insult without any medication. According to the family, he had never before suffered from any attack.

In the above we have limited ourselves to the discussion of the extracardiac influence of pentamethylene-tetrazol on the origin of these attacks. Nevertheless it is not improbable that the administration of much pentamethylene-tetrazol intravenously in reality does cause a lesion of the cardiac muscle. The irregularities observed by Géraudel (1938), Hoogerwerf and Jelerama (1938), and Forschbach (1939) point in this direction.

\section{SUMMARY}

In a patient suffering from schizophrenia, whose electrocardiogram showed a shortened P-R interval and a bundle branch block on four occasions, each time after an intravenous dose of 5.6 c.c. of 10 per cent. pentamethylenetetrazol, an attack of paroxysmal tachycardia was observed, which after a few hours could be abolished by pressure on the eyeballs.

In connection with some further observations in this patient the probable explanation of the genesis of these attacks is discussed.

\section{REFERENCES}

Camp, W. J. R. (1928). J. Pharmacol. exp. Therap., 33, 81.

Danielopolu, D. (1921). Ann. de Med., 10,

Forschbach, G. (1939). Z. Neur., 164, 722.

Galli, G. (1918). Heart, 7, 111.

Géraudel, E. (1938). Arch. Mal. Coeur, 31, 811.

Hildebrant, F. (1937). Handbuch der Exper. Pharm., 5, 151.

Hoogerwerf, S., and Jelgersma, H. C. (1938). Psychiat. en Neurol., 63, 1.

Lewis, T. (1921). Heart, 9, 207.

Lohr, T. (1936). Diss. Groningen.

Rothberger, C. J., and Winterberg, H. (1911). Pflüger's Arch., 41, 343. (1911). Pflüger's Arch., 42, 461.

Scherf, D. (1937). Lehrbuch der Electrokardiographie, Wein.

Schwab, E. H. (1931). Amer. Heart J., 6, 404.

Wolferth, C. C., and Wood, F. C. (1933). Amer. Heart J., 8, 297.

Wolff, L., Parkinson, J., and White, P. D. (1930). Amer. Heart J., 5, 685. 